\title{
NBSIR 77-1409
}

\section{The Equation of State for Ammonia}

Lester Haar

John Gallagher

Equation of State Section

Heat Division

Institute for Basic Standards

National Bureau of Standards

Washington, D.C. 20234

Interim Report

December 1977
QC The Office of Standard Reference Data
100 Vational Bureau of Standards
.U56 Nashington, D.C. 20234
no. $77-1409$
1977 

NBSIR 77-1409

THE EQUATION OF STATE FOR

AMMONIA

Lester Haar

John Gallagher

Equation of State Section

Heat Division

Institute for Basic Standards

National Bureau of Standards

Washington, D.C. 20234

Interim Report

December 1977

This is an interim report. The final report will appear in the Journal of Physical and Chemical Reference Data.

This report is to be superseded by a future publication which will receive general distribution and should be cited as a reference. Please consult the NBS Office of Technical Information and Publications to obtain the proper citation.

Prepared for

The Office of Standard Reference Data

National Bureau of Standards

Washington, D.C. 20234

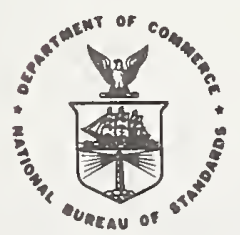

U.S. DEPARTMENT OF COMMERCE, Juanita M. Kreps, Secretary

Dr. Sidney Harman, Under Secretary

Jordan J. Baruch. Assistant Secretary for Science and Technology

NATIONAL BUREAU OF STANDARDS, Ernest Ambler, Acting Director 

The Equation of State for Ammonia*

by

Lester Haar and John Gallagher

\section{Introduction}

This report has been prepared in answer to several urgent requests for detailed computer programs for the thermodynamic properties of ammonia. In it we present a description of an extensive correlation of the thermodynamic properties of ammonia published elsewhere ${ }^{1}$, along with basic equations for the description of the properties of ammonia and detailed listings of computer programs based on these equations. With this information, thermodynamic properties can be calculated for temperatures ranging from the triple point temperature to about $5 / 3$ the critical temperature and for pressures ranging from the dilute gas to about 8000 bars. The reference state for all properties is the ideal gas at zero kelvin. The physical constants used are consistent with those recommended by Cohen and Taylor ${ }^{2}$. The mass of a mole of ammonia was taken to be 17.0306 grams $^{3}$.

2. The derivation of the thermodynamic surface.

In the correlation, selected $P, P, T$ data were fitted to an analytic equation of state in the least squares sense. A detailed discussion of the process of data selection and of selection of parts of the analytic equation is contained in reference 1 . The equation so obtained contains the pressure as a 44 term double power series function of temperature and density. The resulting equation can be used to

* This work was supported by the Office of Standard Reference Data of the National Bureau of Standards. 
reproduce all the available $\mathrm{P}, \rho, \mathrm{T}$ experimental data as well as to produce limited extrapolations (based on thermodynamic arguments) of the surface into important regions where data are sparse. The range of the equation is bounded at low temperatures by the triple point temperature (195.48K) and the melting curve for the liquid, and at high temperatures by the isotherm at $750 \mathrm{~K}$ (which is approximately $5 / 3$ the critical temperature). The pressure range extends to 8,000 bar. No mathematical constraints were imposed on the equation, and only $\mathrm{P}, \rho, \mathrm{T}$ data were used in the least squares fit with the sole exception that values of vapor pressure were explicitly employed in regard to satisfying conditions of phase equilibrium.

Following Keenan et al. 4 the Helmholtz free energy function was represented in reference 1 as the sum of two terms, the first being the contribution from the equation of state and the second a function of temperature only referring to the properties of the ideal gas. Thus the Helmholtz free energy was expressed

$$
A(\rho, T)=\bar{A}(\rho, T)+A^{o}(T)
$$

where $A^{O}(T)$ is the contribution of the ideal gas. $T$ is the absolute temperature in kelvins and $\rho$ the density in grams per $\mathrm{cm}^{3}$. A quantity $Q(\rho, T)$ was defined by

$$
\overline{\mathrm{A}}(\rho, \mathrm{T}) \equiv \operatorname{RT}[\ln \rho+\rho Q(\rho, \mathrm{T})]
$$

Since $\quad P=\rho^{2} \partial A / d \rho$,

Eqs. (1) and (2) yield

$$
P=\rho R T\left[1+\rho Q+\rho^{2} \partial Q / \partial \rho\right] \text {. }
$$


Note that

$$
Q(\rho=0)=B_{2},
$$

where $B_{2}$ is the second virial coefficient. The form chosen for $Q$ was

$$
Q=\sum_{i=1}^{9} \sum_{j=1}^{6} a_{i j} \rho^{i-1}\left(\tau-\tau_{c}\right)^{j-1},
$$

where $\tau=\frac{500}{T}, \tau_{c}=1.2333498$ and $R$ is the gas constant. Eq. (3) for the pressure was fitted in the least squares sense to the experimental $P, P, T$ data. The results of this fit are values for the constants $a_{i j}$ listed in table 1. ( $a_{i j}=0$ for all $i, j$ pairs not listed in table 1$)$. By differentiation of eq (1), the various thermodynamic quantities can. be expressed in terms of $Q$ :

the entropy,

$$
S(\rho, T)=R[\ln \rho+\rho Q-\rho \tau \partial Q / \partial \tau]+S^{\circ}(T)
$$

the internal energy,

$$
E(\rho, T)=R \rho T \tau \partial Q / \partial \tau+E^{O}(T),
$$

the constant volume heat capacity,

$$
C_{v}(\rho, T)=-R \rho \tau^{2} \partial^{2} Q / \partial \tau^{2}+C_{v}{ }^{\circ},
$$


Table 1

1

1

1

1

1

1

1

2

2

2

2

2

2

3

3

3

3

3

3

4

4

4

4

4

4

5

5

5

5

6

6

6

6

7

7

7

7

8

8

8

8

9

9

9

9
J

1

2

3

4

5

6

1

2

3

4

5

6

1

2

3

4

5

6

1

2

3

3

4

5

6

1

2

3

4

1

2

3

4

1

2

3

4

1

2

3

4

1

2

3
A1

$-6.453022304053$

$-13.719926770503$

$-8.100620315713$

$-4.880096421085$

$-12.028775626818$

6.806345929616

8.080094367688

14.356920005615

$-45.052976699428$

$-166.188998570498$

37.908950229818

$-40.730208333732$

1.032994880724

55.843955809332

492.016650817652

1737.835999472605

$-30.874915263766$

71.483530416272

$-8.948264632008$

$-169.777744139056$

$-1236.532371671939$

$-7812.161168316763$

1.779548269140

$-38.974610958503$

$-66.922858820152$

$-1.753943775320$

208.553371335493

21348.946614397509

247.341745995422

299.983915547501

4509.080578789798

$-37980.849881791548$

$-306.557885430971$

24.116551098552

$-9323.356799989199$

42724.098530588371

161.791003337459

$-507.478070464266$

8139.470397409345

$-27458.710626558130$

$-27.821688793683$

298.812917313344

$-2772.597352058112$

7668.928677924520 
the enthalpy function,

$$
H(\rho, T)=R T\left[\rho Q+\rho^{2} \partial Q / \partial \rho+\rho \tau \partial Q / \partial \tau+1\right]+E^{0}(T),
$$

the constant pressure heat capacity,

$$
C_{P}(P, T)=C_{v}+R \cdot \frac{\alpha}{B}
$$

where,

$$
a=1+\rho Q+\rho^{2} \partial Q / \partial \rho-\rho \tau \partial Q / \partial \tau-\rho^{2} \tau \partial^{2} Q / \partial \tau \partial \rho,
$$

and

$$
B=1+2 \rho Q+4 \rho^{2} \partial Q / \partial \rho+\rho \partial^{2} Q / \partial \rho^{2},
$$

the heat capacity for the saturated fluid,

$$
c_{S}=c_{P}-\frac{T}{\rho^{2}} \frac{(\partial P / \partial T)_{\rho}}{(\partial P / \partial \rho)_{T}} \cdot \frac{d P}{d T},
$$

where $P_{S}$ is the vapor pressure of the 11quild.

$S^{0}, E^{0}$ and $C_{v}{ }^{0}$ are the corresponding contributions obtained from $A^{0}(T)$ :

$$
\begin{aligned}
& A^{0}(T)=\left(G^{0}-E_{0}^{0}\right)-\operatorname{RT}(1 \\
& S^{0}=-\frac{d}{d T} A^{0}(T), \\
& E^{0}=A^{0}(T)-T \frac{d A^{0}(T),}{d T}(T) \\
& C_{v}{ }^{0}=-T d^{2} A^{0}(T) / d T^{2},
\end{aligned}
$$


where $G^{0}$ is an analytic representation of the results reported by $\mathrm{Haar}^{5}$ for the properties of the ideal gas state,

$$
\frac{\mathrm{G}^{\circ}-\mathrm{E}_{\mathrm{O}}^{\circ}}{\mathrm{RT}}=\mathrm{a}_{1} \ln \mathrm{T}+\sum_{i=2}^{11} a_{i} \mathrm{~T}^{i-3},
$$

where $\mathrm{E}_{\mathrm{O}}^{\circ}$ is the energy for the ideal gas at $0 \mathrm{~K}$. The coefficients $a_{i}$ are listed in table 2 .

Table 2

$$
\begin{aligned}
& a_{1}=-3.872727 \\
& a_{2}=.64463724 \\
& a_{3}=3.2238759 \\
& a_{4}=-.0021376925 \\
& a_{5}=.86890833 \times 10^{-5} \\
& a_{6}=-.24085149 \times 10^{-7} \\
& a_{7}=.36893175 \times 10^{-10} \\
& a_{8}=-.35034664 \times 10^{-13} \\
& a_{9}=.2056303 \times 10^{-16} \\
& a_{10}=-.6853420 \times 10^{-20} \\
& a_{11}=.9939243 \times 10^{-24}
\end{aligned}
$$

The heat capacity values and the other thermodynamic functions calculated from Eq. (10a) for the temperature range $100 \mathrm{~K} \leq \mathrm{T} \leq 1000 \mathrm{~K}$ agree with those tabulated in reference 5 to within the accuracy of those values. 
Though Eqs. (1-10a) are complete, it is necessary to introduce the Gibbs phase conditions in order to calculate the properties for the coexisting phases. However, it was shown by Haar and Gallagher ${ }^{1}$ that almost negligible error results if an explicit relation is used for the vapor pressure, $\mathrm{P}_{\mathrm{S}}$, obtained by separately fitting the saturated vapor pressure data of Cragoe $^{6}$ for the range from the triple point to $373 \mathrm{~K}$ and of the mean of the data of Beattie and Lawrence ${ }^{7}$ and of Keyes ${ }^{8}$ above $373 \mathrm{~K}$. The equation so obtained is

$$
\log _{e} \frac{\mathrm{P}_{s}}{\mathrm{P}_{c}}=\frac{\mathrm{T}_{c}}{\mathrm{~T}}\left(\mathrm{AX}+\mathrm{Bx}^{3 / 2}+\mathrm{CX}^{5 / 2}+\mathrm{DX}^{5}\right)
$$

where

$$
\begin{aligned}
X & =1-T / T_{C} \\
P_{C} & =111.85 \text { atm. } \\
T_{C} & =405.4 \mathrm{~K} \\
A & =-7.296510 \\
B & =1.618053 \\
C & =-1.956546 \\
D & =-2.114118
\end{aligned}
$$

Eq. (10b) and Eq. (3) define the coexisting phases for this report and all properties over the temperature-pressure range of the thermodynamic surface, subject to the low temperature boundary of the melting solid. The thermodynamic surface is consistent with the following values for the parameters at the triple point,

$$
\begin{aligned}
\mathrm{T}_{t} & =195.48 \mathrm{~K} \\
\mathrm{P}_{t} & =.06063 \mathrm{bar} \\
\rho_{\mathrm{t}}^{\mathrm{g}} & =.00006382 \mathrm{~g} / \mathrm{cm}^{3}, \rho_{t}^{\ell}=.73374 \mathrm{~g} / \mathrm{cm}^{3},
\end{aligned}
$$

and at the critical point,

$$
\begin{aligned}
& \mathrm{T}_{c}=405.4 \mathrm{~K} \\
& \mathrm{P}_{c} \quad 113.04 \mathrm{bar} \\
& \rho_{c}=.2350 \mathrm{~g} / \mathrm{cm}^{3}
\end{aligned}
$$


The relationship between the pressure and temperature of the melting solid was calculated by means of the Clapeyron equation. For the latent heat, the value reported by Overstreet and Giauque ${ }^{9}$ was used; for the specific volume for the solid at the normal melting point, the value reported by McKelvey and Taylor ${ }^{10}$ was used, and for the corresponding specific volume of the liquid the value reported by Cragoe and Harper ${ }^{11}$ was used.

The Clapeyron equation is the relation

$$
\frac{\mathrm{dT}}{\mathrm{T}}=\frac{\mathrm{u}^{\prime}-\mathrm{u}}{\mathrm{L}} \mathrm{dP} \text {, }
$$

where the quantities $u^{\prime}$ and $u$ are the specific volumes of the liquid and solid, respectively, and $\mathrm{L}$ is the latent heat of fusion. From the above data, the quantity $\frac{\mathrm{u}^{\prime}-\mathrm{u}}{\mathrm{L}} \simeq 4 \times 10^{-5} \mathrm{~atm}^{-1}$; and $\mathrm{Eq}$. (11) can be integrated to yield

$$
T=T_{S} \exp \left[4 \times 10^{-5}\left(P-P_{S}\right)\right]
$$

where $\mathrm{T}_{\mathrm{S}}$ and $\mathrm{P}_{\mathrm{S}}$ are the triple point values. (The differences between the triple point values and those of the normal melting point are negligible.) Also, since $\mathrm{P}_{\mathrm{S}}$ at the triple point is very small, the relationship can be simplified to

$$
\mathrm{T}=195.48 \exp \left\{4 \times 10^{-5} \mathrm{P}(\mathrm{atm})\right\} .
$$




\section{Computer programs.}

The properties calculated from the equations presented in this report have been compared with the various thermodynamic measurements reported for ammonia in the comprehensive review in reference 1 . In almost al1 cases the agreement is within the experimental accuracy of the data. Comparisons of results with $\mathrm{P}, \rho, \mathrm{T}$ data are given here in figures 2 and 3 . It was established in reference 1 that for most of the vapor phase and for the coexisting phases, the calculated enthalpies are accurate to within $0.1 \%$.

To facilitate the application of these results we present in Appendices I through IV computer programs in FORTRAN with which the various properties of ammonia can be calculated. Four such programs are included:

The computer program in Appendix I is a general program for all the thermodynamic properties discussed in section 2 of this report, including the program for the calculation of $\mathrm{Q}$ of $\mathrm{Eq} .(4)$ and its derivatives with respect to temperature and density which are used by most of the other programs. The independent variables are either pressure and temperature or density and temperature.

The computer programs in Appendix II refer only to certain properties for the coexisting phases, including the latent heat of vaporization, the vapor pressure of the saturated liquid, the densities of the saturated vapor and of the saturated liquid and the heat capacity of the saturated fluid. The dependent variable for these is either the temperature or the corresponding pressure of the saturated liquid.

As all of the above programs assume densities in $\mathrm{g} / \mathrm{cm}^{3}$, temperatures in kelvins and pressure in atmospheres, a set of simple routines is presented in Appendix III for conversions back and forth between these units and other commonly used systems of units. 
Appendix IV contains examples of typical calculations using the routines for Appendices I through III.

Al1 quantities other than pressure, density and temperature are calculated and used in dimensionless units. Results in two commonly used systems of units can be obtained as follows:

To obtain heat capacities and entropy in SI units (joules/g), multiply the dimensionless quantities by 0.48820 ; or in Btu/1b., multiply the dimensionless quantity by 0.210027 .

To obtain enthalpies, internal energies or heats of vaporization in SI units (joules/g K), multiply the dimensionless quantities by $(0.48820 \mathrm{~T})$ where $\mathrm{T}$ is in $\mathrm{K}$; or in $\mathrm{Btu} / \mathrm{lb}$. $\operatorname{deg} \mathrm{F}$, multiply the dimensionless quantities by $(0.210027 \mathrm{~T})$ where $\mathrm{T}$ is in deg $\mathrm{R}$.

The programs as presented are in single precision except for the coefficients of the generating function ' $Q$ ', which are in double precision. This will give accuracy to within the limits of the equation when used on most computers. (When used on computers with word lengths of 48 bits or more, even these coefficients may be used in single precision.) If more precision is needed, the following can be made double precision in all routines: T, P, D, Q01, Q02, Q10, Q20, Q11. The greater precision may be required when making calculations at liquid densities or in the vicinity of the critical point, particularly when obtaining values for the thermodynamic functions requiring higher derivatives of the generating function $Q$, such as, for instance, $C_{p}$. In these cases the contributions of all of the 44 terms are of importance, as there is much cancellation of contributions from individual terms. 
1. L. Haar and J. Gallagher, Thermodynamic Properties for Ammonia, submitted for publication in the Journal of Physical and Chemical Reference Data.

2. E. R. Cohen and B. N. Taylor, Fundamental Physical Constants, J. Phys. Chem. Ref. Data 2 , No. 4, 663 (1973).

3. A. E. Cameron and E. Wickers, Report on the International Committee on Atomic Weights (1961). J. Am. Chem. Soc. 84, 4192 (1962).

4. J. F. Keenan, F. G. Keyes, P. G. Hill, and J. G. Moore, Steam Tables, John Wiley and Sons, New York (1969).

5. L. Haar, Thermodynamic Properties of Ammonia as an Ideal Gas, J. Research N.B.S. 72A, 207 (1968).

6. C.S. Cragoe, C.H. Meyers and C.S. Taylor, Vapor Pressure of Ammonia, Sci. Pap. Bur. Stand. 16, 1 (1920).

7. J.A. Beattie and C.K. Lawrence, Some of the Thermodynamic Properties of Ammonia, I. The Compressibility and an Equation of State for Ammonia, J. Am. Chem. Soc. 52, 6 (1930).

8. F.G. Keyes and D.B. Brownlee, The Vapor Pressure of Liquid Ammonia up to the Critical Temperature. J. Am. Chem. Soc. 40, 25 (1918).

9. R. Overstreet and W.F. Giauque, Ammonia, The Heat Capacity and Vapor Pressure of Solid and Liquid, Heat of Vaporization, The Entropy Values from Thermal and Spectral Data, J. Am. Chem. Soc. 59, 254, (1937).

10. E.C. McKelvey and C.S. Taylor, Composition, Purification, and Certain Constants of Ammonia. Sci. Pap. Bur. Stands. 18, 655 (1923).

11. C.S. Cragoe and D.R. Harper, 3d, Specific Volume of Liquid Ammonia, Sci. Pap. Bur. Stands. 17, 287 (1921).

12. C.H. Meyers and R.S. Jessup, The Specific Volume of Superheated Ammonia Vapor, Refrig. 11, 345 (1925). 
13. C.S. Cragoe, E.C. McKelvey, and G.F. O'Connor, Specific Volume of Saturated Ammonia Vapor, Sci. Pap. Bur. Stands. 18, 655 (1923).

14. J.S. Kazarnowsky, The Compressibility of Ammonia at High Temperatures and High Pressures, Acta. Phys. Chim. U.S.S.R. 12, 513 (1940).

15. F.G. Keyes, The Pressure-Volume-Temperature Values for Ammonia to One Thousand Atmospheres, J. Am. Chem. Soc. 533, 965 (1931).

16. K. Date, Studies on the P-V-T Relations of Fluids at High Pressures, I. The Compressibility of Ammonia, Rev. of Phys. Chem. of Japan 43, 1 (1973).

17. A. Kumagai and T. Toriumi, Pressure-Volume-Temperature Relationship of Liquid Ammonia, J. of Chem. and Eng. Data 16, 293 (1971).

18. D.S. Tsiklis, Compressibility of Ammonia Under Pressures to 10,000 Atmospheres, Acad. of Sci. U.S.S.R. 91, 889 (1953).

19. A. Harlow and E.U. Frank, private communication from E.U. Frank.

20. K. Date, Studies of PVT Relations of Fluids at High Pressures, II. Relations for Ammonia in the Neighborhood of the Critical Point and the Critical Values for Ammonia, Rev. of Phys. Chem. Japan 43, 17 (1973). 
PACKAGE OF FORTRAN PRJGRAMS TO GENERATE THE THERMODYNAMI C PROPERTIES OF AMMONIA FOR ENTIRE REGION.

SUBROUTINE QOROL,K,T,DJ

THIS IS THE GENERATING FUNCTION FOR Q AND ITS JERIVATIVES USED IN THE CALCULATION OF THE OTMER FUNCTIONS. O IS GENERATED AS A FCT OF $T$ AND D. AND $L$ IS THE ORDER JF THE DERIVATIVE OF O WITH RESPECT TO RECIPROCAL TEMP. ANO K IS THE ORDER OE THE DERIV. W.R.T. DENSITY. DOUBLE PRECISION A.A1.A2,DD.C.TT, OT

DIMENSION P(5.5), DO(10).TT(7).A(44), II(44),JJ(44), AI(22).A2(22) EQUIVALENCE (A1(1), A(1)).(A2(1). A(23)

DATA II/6*1.6*2.6*3.6*4.4*5.4*6.4*7.4*8.4*9/N/44/

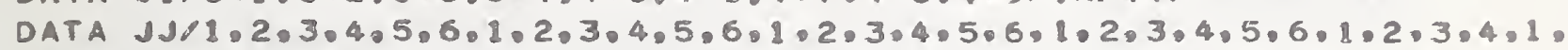

$12.3 .4 .1 .2 \cdot 3 \cdot 4 \cdot 1.2,3.4,1.2,3,4 /$

DATA P/2..2..3..4..5.

$124 . .48 .0120 .05 \cdot 20.060 .120 . \cdot 240 . /$

DATA A $1 /-6.4530223040500 .-13.719926770500 .-8.100620315700 .-4.88009$ $1642100,-12.028775626800,6 \cdot 8063459300.8 .0800943676900 .14 .3569200060$ $20 .-45.052976700 .-166.1889985700 .37 .9089502300 .-40.730208333700$.

31.032994880700 .55 .8439558100 .492 .016650817700 .1737 .83600 .

$4-30.87491526376600 .71 .48353041600 .-8.94826463200 .-169.7777441400$.

$5-1236.5323716700,-7812 \cdot 16116831700 /$

DATA A2/1.7795482691400, $-38.9746109600 .-66.9228588200 .-1.75394377532$

$13200 \cdot 208 \cdot 55337133500 \cdot 21348 \cdot 946600 \cdot 247 \cdot 34174600 \cdot 299 \cdot 9939155500.4509$

$2.0805797900,-37980.8500,-306.5578854300 \cdot 24 \cdot 116551100 .-9323.356800$.

$342724.098530600 \cdot 161.7910033374600 .-507.47807046450 \cdot 3139 \cdot 470397400$.

$4-27458 \cdot 7106300 .-27.821688800 \cdot 298.812917300 .-2772.59735200$.

$57668.92867800 /$

$Q=0$.

IF $(L+K) 12 \cdot 14,18$

12 RETURN

$14 U=500 . / T$

$C=U-1.23334977800$

IF (DABS $(C) \cdot L T \cdot 1 \cdot D-8) C=1 \cdot D-8$

$\operatorname{TT}(1)=1$.

DO $15 \quad I=2,7$

15 TT(I) $=T(T(I-1) * C$

IF $(D \cdot L T \cdot 1 \cdot E-8) \quad D=1 \cdot E-8$

$D D(1)=1$.

DO $16 \quad I=2,10$

$16 \mathrm{DO}(\mathrm{I})=\mathrm{DO}(\mathrm{I}-1) * 0$

$1800200 \quad M=1 \cdot N$

$I=I I(M)$

$J=J j(M)$

IF $(J-L-1) \quad 200 \cdot 20 \cdot 30$

20 IF(L) $200,24,28$

24 OT $=1$.

GO TO 50

$28 Q T=P(L . L) / 2$.

GO TO 50

30 IF (L) 200.32 .40

32 OT $=T T(J)$

GO TO 50

40 QT $=P(L, J=1) * T T(J-L)$

50 IF (K) 200.60 .70 
$60 \mathrm{QT}=\mathrm{QT} * \mathrm{DD}(\mathrm{I})$

GO TO 100

$70 R=1$.

DO $72 M M=1, K$

$72 R=R *(I-M M)$

$Q T=Q T * R * D D(I-K)$

$100 \quad Q=Q+A(M) * 0 T$

200 CONTINUE

RETURN

END

$c$

SUBROUTINE FZ(T.FO,SO,CPO.UO)

c

COMPUTES THE IDEAL GAS FUNCTIONS AS FCT OF T: FREE ENERGY(FO/RT)

C ENTROPY $(S O / R)$ : $C P(C P O / R)$ :

DIMENSION A(12)

DATA A/ $-3.872727 .064463724 .3 .2238759,-.0021376925 . .86890833 E-5$.

$1=24085149 E-7.036893175 E-10,-35034664 E-13.020563027 E-16$.

$2-.685342 E-20, .99392427 E-24.0 . /$

$U=T$

IF (T.LE.10.) $U=10$.

$F O=A(1) * A L D G(U)+A(2) / U+A(3)+A(4) * U+A(5) * U * U+A(6) * U * * 3+A(7) * U * * 4$

$1+A(8) * U * * 5+A(9) * U * * 6+A(10) * U * * 7+A(11) * U * * 8$

$S O=A(1) *(A L O G(U) * 1)+.A(3)+2 \cdot * A(4) * U+3 \cdot * A(5) * U * U+4 \cdot * A(6) * U$

$1 * 3+5 * * A(7) * U * * 4+6 . * A(8) * U * * 5+7 \cdot * A(9) * U * * 6+8 * A(10) * U * * 7$

$2+9 \cdot * A(11) * U * 8$

$C V 0=A(1) / U+2 * * A(4)+6$. *A( 5$) * U+12 * A(6) * U * U+20 \cdot * A(7) * U * * 3+30 * A(8) *$

$1 U * * 4+42 \cdot * A(9) * U * * 5+56$.*A(10)*U**6+72**A(11)*U**7

$C V O=-C V O * U$

$S O=-S O$

$U O=S O \& F O-1$.

RETURN

END

C

FUNCTION PRESID.T)

C PRES CALCULATES THE PRESSURE IN ATMJSPHERES USING D,T,Q AND DQ/D(D). COMMON /000Q/ Q00.001.002.010.020.011

PRES $=4.818 * T * D *(1 .+D *(000+D * 001))$

RETURN

END

C

FUNCTION DPDD(D,T)

C DPDD CALCULATES THE DERIVATIVE OF THE PRESSURE(IN ATMI WITH RESPECT

C TO DENSITY (IN GM/CC).

COMMON /0000/ 000,001,002,010.020.011

DPOD $=4.818 * T *(1 .+2 * D * 000+D * D *(4 . * 001+D * 002))$

RETURN

END

C

FUNCTION ENTR(D.T.SO)

C CALCULATES THE ENTROPY IN DIMENSIONLESS UNITS (S/RI. REQUIRES

C PRIOR CALL TO FZ, QOO AND Q10

COMMON /QQQQ/ 000.001.002.010.020.011

$U=500 \cdot 1 T$

$T D=T * D$

$I F(T D \cdot L T \cdot 1 \cdot E-6) T D=1 \cdot E-6$

$E N T R=5 I G+D \neq U * 010-D * 000-A L D G(4.818 * T D)$

RETURN

END 
C

FUNCTION ENTHPD.T.ENER)

C CALCULATES THE ENTHALPY IN DIMEMSIONLESS UNITS (H/RT). REQUIRES

C PRIOR CALL TO ENER. FZ.000.001 AND Q10.

COMMON /0000/ 000.001.002.010.020.011

ENTHEENER + 1. *D*000+D*D*001

RETURN

END

C

FUNCTION ENER(D.T. UO)

C CALCULATES THE INTERNAL ENERGY IN DIMENSIONLESS UNITS (U/RT).

C REQUIRES PRIOR CALL TO FZ. QOO AND OIO

COMMON /0000/ 000.001.002.010.020.011

$U=500 . / T$

$E N E R=D * U * 010+U 0$

RETURN

END

C

FUNCTION CVIO.T,CPOI

C CALCULATES THE hEAT CAPACITY AT CONST VOLUME IN DIMENSIONLESS

C UNITS (CVIR). REQUIRES PRIOR CALLS TO FZ, 0OO AND O2O.

COMMON /0000/ 000.001.002.010.020.011

$U=500 . / T$

$C V=C P 0-1,-D * U * U * 020$

RETURN

END

C

FUNCTION CP(D.T.CV)

C CALCULATES THE HEAT CAPACITY AT CONST PRESSURE IN DIMENSIONLESS

$C$ UNITS (CP/R). REQUIRES PRIOR CALLS TO FZ, 000. 0O1.002, Q10. 020,

C QII AND CV.

COMMON $10000 / 000.001 .002 .010 .020 .011$

$U=500 \cdot / T$

$C P=(1 .+0 *(000-U * 010+D *(001-U * 011)) * 2 /(1-* 0 *(2 \cdot * 000 * 0 *(4 . * 001 * D *$

$10021) 1+C V$

RETURN

ENO

C

SUBROUTINE OFINDIDQUT,P,D,T,DPDI

C THIS SUBROUTINE, BY AN ITERATIVE PRJCESS USING THE =UNCTIONS

C PRES AND DPDD. WILL CALCULATE THE DENSITY AS A FCT OF A GIVEN

C PRESSURE AND TEMPERATURE. THE REQUIRED INPUTS ARE P, T. AND

$C$ DIWHICH IS AN INITIAL GUESS FOR THE OENSITYI. THE OUTPUTS ARE

$C$ DOUT (THE DENSITY CONSISTANT UITH THE INPUTS D AVD T) AND DPD

$C$ (THE VALUE OF DP/OD AT $P$ AND $T$. THE VALUES OF P ARE IN ATM.

C T IN K. AND D AND DOUT IN G/CC. NOTE THAT FOZ T LESS THAN TC.

C AND FOR P ANO T NEAR THE COEXISTANCE CURVE. CARE MUST BE USED IN

C THE SELECTION OF THE INITIA. GUESS FOR D SO THAT SPURIOUS VALUES

C IN THE TWO PHASE REGION ARE NOT RETURNED.

COMMON /OQ00/ 00.01.02.010.020.011

$O D=D$

$L=0$

$9 L=L+1$

IF $(00 \cdot L E \cdot 0 \cdot) \quad D D=1 \cdot E-8$

IF $(D D \cdot G T \cdot .85) \quad D O=.85$

CALL OO $(00.0 .0 . T .00)$

CALL OQ101.0.1.T.001

CALL OQ $(02.0 .2, T .00)$ 


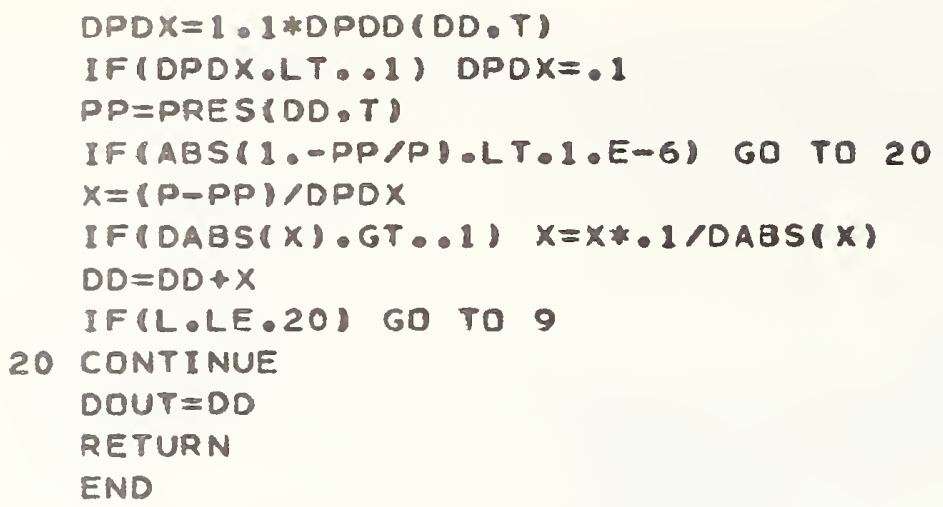


C

$c$

C

C

C

c
APPENDIX II

FORTRAN PROGRAMS FOR FUNCTIONS PERTAINING TO COEXISTANCE LINE

\section{FUNCTION PS(T)}

PS CALCULATES THE VAPOR PRESSURE (IN ATM) AS A FCT OF T IN K. FOR T GREATER THAN TC, O. IS RETURNED.

DIMENSION A(4)/-7.296510.1.618053,-1.956546.-2.114118/

IF $(T \cdot G T \cdot 405.4)$ GO TO 10

$T H=T / 405.4$

$T M=1 . T H$

TS=DSORT (TM)

$P=T M * T S$

$Q=P * T M$

$R=0 * 0$

$F=(A(1) * T M+A(2) * P+A(3) * Q+A(4) * R) / T H$

$P S=111 \cdot 85 * E X P(F)$

RETURN

10 PS $=0$.

RETURN

END

C

FUNCTION DPSOT(T)

C CALCULATES THE DERIVATIVE OF THE VAPOR PRESSUZE CURVE WITH

C RESPECT TO T. FOR T GREATER THAN TC. THE VALUE 2.03 (THE APPROX-

C IMATE VALUE AT TC) IS RETURNED.

DIMENSION A(4)/-7.296510.1.618053.-1.956546.-2.114118/

IF (T.GT.405.4) GO TO 10

$T H=T / 405.4$

$T M=1 .-T H$

$T S=S O R T(T M)$

$P=T M * T S$

$Q=P * T M$

$R=Q * Q$

$F=(A(1) * T M+A(2) * P+A(3) * Q+A(4) * R) / T H$

$P S=111 \cdot 85 * \operatorname{EXP}(F)$

$S=P * Q$

DPSDT $=(-F-A(1)-1 \cdot 5 * A(2) * T S-2 \cdot 5 * A(3) * P-5 \cdot * A(4) * S) * P S / T$

RETURN

10 DPSDT $=2.03$

RETURN

END

c

FUNCTION TS(P)

C CALCULATES BY AN ITERATIVE METHOD USING PSITI AND GENERATING

C A STARTING VALUE BY AN APPROXIMATE EQUATION. THE SATURATION TEMPERATURE

C AS A FUNCTION OF THE PRESSURE IV ATM. IF P LESS THAN THE TRIPLE POINT

C VALUE OR GREATER THAN PC, O IS RETURNED.

$Q=1 \cdot / P$

IFPP.GT..058.AND.P.LT.111.85) GO TO 4

$T S=0$.

RETURN

4 CONTINUE

$T=252.10703+P *(5.6658636+P * 1-.12457077+P *(.00135987$

$1-P * .00000531942) 1)+Q *(-15.379678+Q *(1.528315-0 * .04906))$

5 P X $=P S(T)$

IF (ABS(1.-P/PX) LT.1.E-5) GO TO 10 


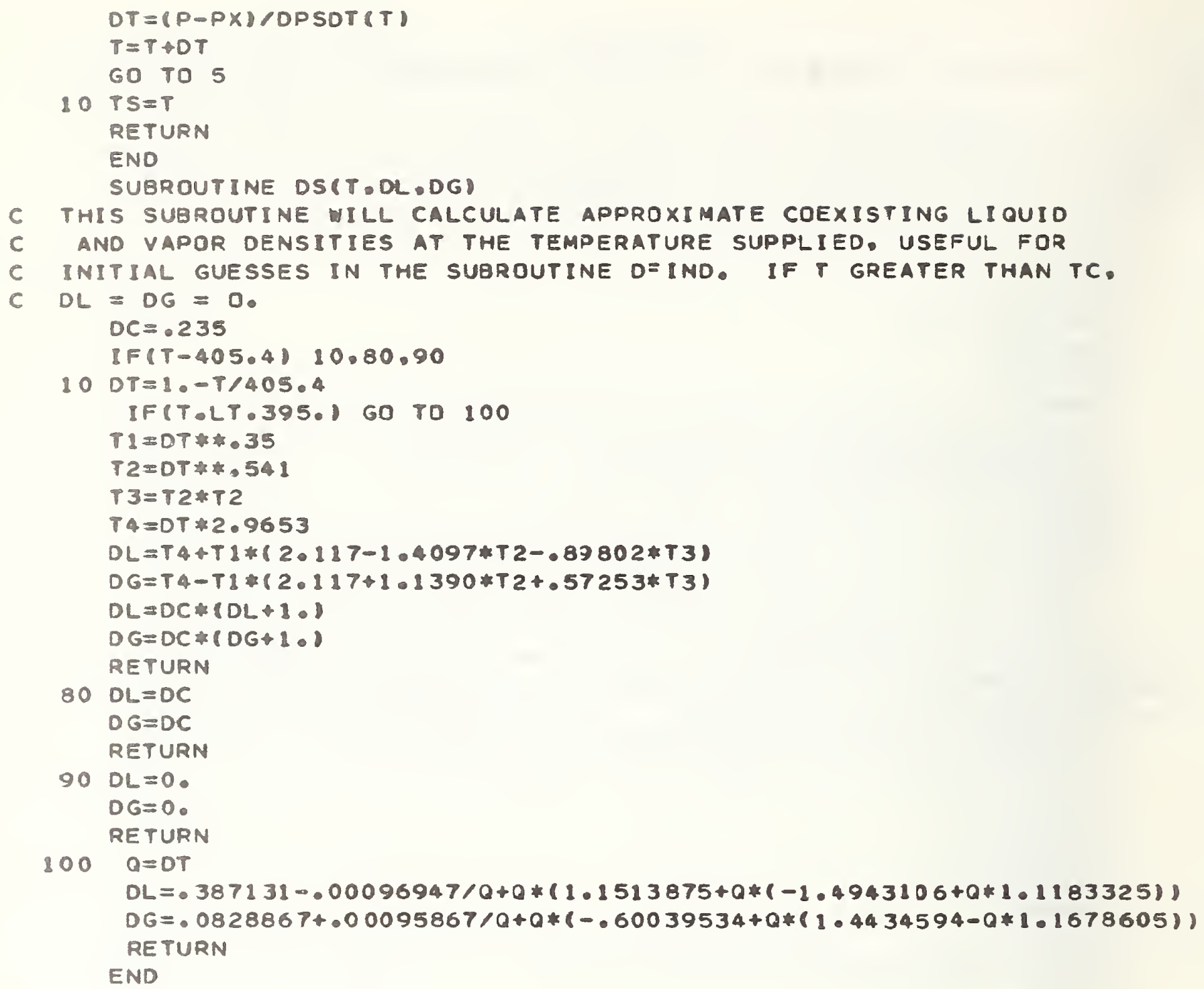

THIS FUNCTION WILL CALCULATE THE HEAT OF VAPORIZATION IN DIMENSIONLESS UNITS (L/RT) AT THE INPUT TEMPERATURE T. DL AND DG ARE REQUIREO TO BE PREVIOUSLY CALCULATED AND SUPPLIED AS INPUT $U=500 \cdot / T$

CALL OQ(OO.0.0.T.DL)

CALL OOIO1,0,1.T.DL)

CALL $00(02,1 \cdot 0, T \cdot O L)$

CALL OQ(RO, 0.0.T,DG)

CALL QQR $R 1,0,1, T, D G)$

CALL OQ(R2,1,0,T,DG)

$H V=U *(D G * R 2-D L * 02)+D G *(R 0 * D G * R 1)-D L *(00+D L * Q 1)$

RETURN

END

C

FUNCTION CS(D.T.CPR)

C CALCULATES THE HEAT CAPACITY OF THE SATURATES FLUID IN

C DIMENSIONLESS UNITS (CS/R). INPUTS ARE D.T AND THE DIMENSIONLESS

C CP/R CALCULATED PRIOR TO THE CALL.

COMMON /OQQQ/ 000.001.002.010.020.011

TDPOT $=P R E S(D, T)-D * 500 * 4.818 * D *(010 * 0 * 011)$

$C S=C P R-T O P D T / O P D D(D, T) / 0 / D * D P S O T(T) * .101325$

RETURN

END 
FUNCTION TK(TF)

$T K=(T F+459.67) * 5.19$.

RETURN

END

C

FUNCTION TF(TK)

$T F=1.8 * T K-459.67$

RETUFN

END

C

FUNCTION PATM(PSIA)

PATM $=$ PSIA/ 14.696

RETURN

END

C

FUNCTION PSIA (PATM)

PSI A=PATM*14.696

RETURN

END

C

FUNCTICN PAT (PBAR)

$P A T=P B A R / 1.01325$

FETURN

END

C

FUNCTION PBAR (PATM)

$P R A R=P A T M * 1.01325$

RETUFN

END

C

FUNCTION DGCC (DLACF)

DGCC $=$ DLBCF/62.428

RETURN

END

c

FUNCTION DLBCF(DGCC)

$D L B C F=D G C C * 62.428$

FETURN

END 


\section{APPENDIX IV \\ EXAMPLES OF USE OF PROGRAMS IN ABOVE PACKAGES}

THE FOLLJWING SAMPLE PROGRAY WILL CALCULATE THE DENSITY AND FIVE THERMOOYNAMIC FUNCTIONS AT A POINT (P,T) SUPPLIED. P SUPPLIED IN BAR, T IN DEG C, DENSITY IN GM/CC, CP,CV,S IN JOULES/GM DEG C, AND INTERNAL ENERGY. ENTHALPI

IN JOULES/GM.

COMMON /0000/ 000.001 .002 .010 .020 .012

1 READ 2, PBAR,TC

2 FORMAT $(2 F 10.3 . F 10.6,2 F 10.3,3 F 10.5)$

P=PATM(PBAR)

IF (P.LE.O.) STOP

$T=T C+273.15$

$C A L L P M A S E(P, T, D, D G, K)$

$I F(K, E Q,-1)$ GO TO 1

CALL DFIND (D,P,DL,T,DX)

CALL QQ(010.1.0.T.D)

CALL $00(020,2,0, T . D)$

CALL QQ(O11.1.1.T.D)

CALL FZ(T.FO,SO,CVO,EO)

$C V V=C V(D, T, C V O)$

$C P P=C P(D, T \cdot C V V) * .4882$

$C V V=C V V * .4882$

$S=E N T R(D, T \cdot S O) * .4882$

$E=E N E R(D, T, E O)$

$H=E N T H(D, T, E) * .4882 * T$

$E=E * .4882 * T$

PRINT 2,PBAR,TC,D,H,E,S,CPP,CVV

GO TO 1

END

A SAMPLE PRDGRAM TO CALEULATE THE SATURATION TEMPERATURE IN DEG F, DENSITIES IN LB/CU FT, AND HEAT OF VAPORIZATION IN BTU/LB AT A GIVEN PRESSURE IN PSIA

READ 1. PSI

1 FORMAT $(5 F 10.3)$

P=PATM(PSI)

$T=T S(P)$

CALL DS(T॰XDL,XDG)

CALL DF IND (DL,P,XDL, T,DX)

CALL DFIND (DG,P,XDG,T,DY)

$H M=H V(T, D L, D G) * .210027 * T$

$D L=D L B C F(D L)$

$D G=D L B C F(D G)$

PRINT 1. PSI,TT,DL,DG,HH

STOP

END 
NBS-114A (REV. 7*73)

\begin{tabular}{|c|c|c|c|}
\hline $\begin{array}{l}\text { U.S. DEPT. OF COMM. } \\
\text { BIBLIOGRAPHIC DATA } \\
\text { SHEET }\end{array}$ & $\begin{array}{l}\text { 1. PUBLICATION OR REPORT NO. } \\
\text { NBSIR } 77-1409\end{array}$ & $\begin{array}{l}\text { 2. Gov't Accession } \\
\text { No. }\end{array}$ & 3. Recipient's Accession No. \\
\hline \multirow{2}{*}{\multicolumn{3}{|c|}{$\begin{array}{l}\text { 4. TITLE AND SUBTITLE } \\
\text { The Equation of State for Ammonia }\end{array}$}} & $\begin{array}{l}\text { 5. Publication Date } \\
\text { December } 1977 \\
\end{array}$ \\
\hline & & & 6. Performing Organization Code \\
\hline \multicolumn{3}{|c|}{$\begin{array}{l}\text { 7. AUTHOR(S) } \\
\text { Lester Haar and John Gallagher }\end{array}$} & 8. Performing Organ. Report No. \\
\hline \multirow{2}{*}{\multicolumn{3}{|c|}{$\begin{array}{l}\text { 9. PER FORMING ORGANIZATION NAME AND ADDRESS } \\
\text { NATIONAL BUREAU OF ST ANDARDS } \\
\text { DEPARTMENT OF COMMERCE } \\
\text { WASHINGTON, D.C. } 20234\end{array}$}} & $\begin{array}{l}\text { 10. Project/Task/Work Unit No. } \\
2210147\end{array}$ \\
\hline & & & 11. Contract/Grant No. \\
\hline \multirow{2}{*}{\multicolumn{3}{|c|}{ 12. Sponsoring Organization Name and Complete Address (Street, City, State, ZIP) }} & $\begin{array}{l}\text { 13. Type of Report \& Period } \\
\text { Covered Interim }\end{array}$ \\
\hline & & & 14. Sponsoring Agency Code \\
\hline
\end{tabular}

15. SUPPLEMENTARY NOTES

16. ABSTRACT (A 200-word or less factual summary of most significant information. If document includes a significant bibliography or literature survey, mention it here.)

An outline is presented of the basic results of the extensive correlation for the thermodynamic properties of ammonia recently completed at this laboratory. Computer programs are presented for the calculation of thermodynamic properties in the range including the triple point temperature to $5 / 3$ the critical temperature and pressures from the dilute gas to 8000 bar.

17. KEY WORDS (six to twelve entries; alphabetical order; capitalize only the first letter of the first key word unless a proper name; separated by semicolons) Ammonia; correlation; gas; 1iquid; thermodynamic properties; thermodynamic surface.

\section{AVAILABILITY

$$
\bar{x} \text { Unlimited }
$$

For Official Distribution. Do Not Release to NTIS

$\square$ Order From Sup. of Doc., U.S. Government Printing Office Washington, D.C. 20402, SD Cat. No. CI3

[.] Order From National Technical Information Service (NTIS) Springfield, Virginia 22151

\begin{tabular}{|l|c|}
\hline $\begin{array}{l}\text { 19. SECURITY CLASS } \\
\text { (THIS REPURT) }\end{array}$ & 21. NO. OF PAGES \\
UNCL ASSIFIED & 22 \\
\hline $\begin{array}{l}\text { 20. SECURITY CLASS } \\
\text { (THIS PAGE) }\end{array}$ & 22. Price \\
UNCLASSIFIED & $\$ 4.00$ \\
\hline
\end{tabular}



